\title{
UM OLHAR DA ANTROPOLOGIA DAS PAISAGENS E ESPAÇOS SOBRE O RITUAL
} DE UKANYI

\author{
Dulcídio M. A. Cossa ${ }^{1}$
}

\section{Resumo}

Neste artigo pretendo incitar um debate assente no entrelaçamento entre o ritual de $u k a n y i^{2}$ e as noções de espaços e lugares, lugares de memória e morfologia social. Assim, proponho uma discussão que permita um entrosamento entre as perspectivas de Michel de Certeau, François Hartog, Marcel Mauss e o ritual de ukanyi. A partir da compreensão de que forma ou até que ponto tal ritual pode exercer a influência sobre as relações sociais e as dinâmicas do espaço rural e urbano reconfigurando-os em antropologicamente construídos proponho pensar os espaços de realização do ritual de ukanyi enquanto lugares de memória e de que modo a morfologia social de Marracuene e Macuane (meus campos de pesquisa) pode ser relativamente modificada à luz da realização do ritual numa determinada época do ano. Para tanto, metodologicamente, opto em um debate baseado na discussão teórica de algumas perspectivas da antropologia das paisagens e espaços capaz de permitir não só a compreensão do ritual de ukanyi, mas também das dinâmicas dos espaços rural e urbano.

Palavras-chave: Ritual de ukanyi; Espaços e Morfologia Social.

\begin{abstract}
In this article I intend to incite a debate based on the interweaving between ukanyi ritual and the notions of spaces and places, places of memory and social morphology. Thus, I propose a discussion that allows a connection between the perspectives of Michel de Certeau, François Hartog, Marcel Mauss and the ukanyi ritual. From the understanding of how or to what extent such a ritual can exert influence on social relations and the dynamics of rural and urban space by reconfiguring them in anthropologically constructed I propose to think the spaces of realization of ukanyi ritual as places of memory and that the social morphology of Marracuene and Macuane (my fields of research) may be relatively modified considering the ritual at a given time of year. For this, methodologically, I opt in a debate based on the theoretical discussion of some

\footnotetext{
${ }^{1}$ Doutorando do Programa de Pós-graduação em Ciências Sociais da Universidade do Estado do Rio de Janeiro UERJ. E-mail: dmacossa@gmail.com

${ }^{2}$ Ritual de ukanyi é uma festa realizada no sul de Moçambique para beber e celebrar ukanyi (bebida tradicionalsagrada).
} 
perspectives of the anthropology of landscapes and spaces capable of allowing not only the understanding of ukanyi ritual, but also of the dynamics of rural and urban spaces.

Keywords: Ukanyi Ritual; Spaces and Social Morphology. 


\section{Considerações iniciais}

O presente artigo inicia com a parte introdutória, na qual constam os objetivos, a metodologia e a relevância teórica do trabalho, em seguida é feita uma breve descrição do ritual de $u k a n y i$, assunto central deste trabalho e depois uma apresentação das perspectivas dos autores com os quais articularei o debate. Na sequência a discussão propriamente dita, figura-se assente no entrelaçamento entre o ritual de ukanyi e as noções de espaços e lugares, lugares de memória e morfologia social, encerrando com as considerações finais.

Proponho uma discussão que permita um diálogo entre as perspectivas de Michel de Certeau, François Hartog, Marcel Mauss e o ritual de ukanyi. Dessa maneira, procuro como fulcrais objetivos entender de que forma ou até que ponto o ritual de ukanyi pode exercer influência sobre as relações sociais e as dinâmicas do espaço rural e urbano reconfigurando-os em espaços antropologicamente construídos, além de pensá-los enquanto locais compreendidos como lugares de memória. Constitue ainda meu objetivo perceber em que medida a morfologia social de Maputo (Marracuene) ${ }^{3}$ e Macuane $^{4}$ (meus campos de pesquisa) podem ser relativamente modificados à luz da realização do ritual de ukanyi numa determinada época do ano.

Para a consecução do trabalho, do ponto de vista metodológico, optei em um debate que pautasse pela análise qualitativa e baseada na discussão teórica de algumas perspectivas da antropologia das paisagens e espaços tendo como alicerces os dados da minha dissertação de mestrado.

Espera-se que este estudo possa permitir não só a compreensão do ritual de ukanyi, mas também a análise das dinâmicas dos espaços (rural e urbano), ou seja, que através da compreensão do ritual se possa entender simultaneamente as relações sociais que perfazem e permitem a praticidade dos espaços.

\footnotetext{
${ }^{3}$ Marracuene é uma vila situada na província de Maputo e faz parte dos dois postos administrativos que compõem o distrito de Marracuene, respetivamente: Machubo e Marracuene. Disponível em https://pt.wikipedia.org/wiki/Marracuene_(distrito). Acessado em: 22 Mai. 2015.

${ }^{4}$ Macuane é um posto administrativo que integra as localidades de Chichango, Macuane e Tuane Oriental e faz parte dos seis postos administrativos que compõem o distrito de Bilene, de entre os quais: Chissano, Macia, Mazivila, $\begin{array}{llllll}\text { Messano } & \text { e } & \text { Praia } & \text { do } & \text { Bilene. }\end{array}$ http://pt.wikipedia.org/w/index.php?title=Bilene_Macia_(distrito)\&oldid=27509127. Acessado em: 2 Abr. 2012.
} 


\section{Breve descrição do ritual de $u$ kanyi ${ }^{5}$}

Entre os meses de janeiro e março, algumas comunidades das províncias de Maputo, Gaza e Inhambane, na região sul de Moçambique, celebram a época de ukanyi. Época tradicionalmente tida como Nguva ya Ukanyi ${ }^{6}$ é o período em que se realiza uma série de rituais afins a ukanyi, momento de efervescência coletiva, caracterizado por uma forte movimentação de pessoas motivadas por esta série de rituais. Justamente é a ocasião em que a abundância do canhú (tanto fruto e como bebida) se faz presente no cotidiano dos indivíduos. Assim, a época de ukanyi vai desde a frutificação do canhú, a coleta deste fruto, a produção da bebida ukanyi até a realização dos rituais comuns à bebida e à época.

Ukanyi $^{7}$ é uma bebida produzida a partir dos frutos do canhoeiro, cientificamente conhecido como Sclerocarya birrea, uma árvore fruteira que ocorre em alguns países do continente africano tais como Moçambique, África do Sul, Namíbia, Suazilândia, Zimbabue, Botsuana, na África Equatorial (entre a Etiópia e o Sudão, a norte), entre outros. Aqui interessa o contexto moçambicano, onde localmente o canhoeiro tem o nome de nkanyi ${ }^{8}$, pelo menos na região sul do país, sendo, segundo Valoi (2010), ukanyi uma bebida dotada de um grande valor sociocultural neste contexto, concretamente no sul do país.

O ritual é parte integrante de uma série de rituais da época de ukanyi (nguva ya ukanyi) que comporta três etapas fundamentais e indissociáveis: kuhawula mindzheko, xikuwha $e$ kuhayeka mindzheko, sem as quais o sucesso da época de ukanyi fica comprometido.

De acordo com Valoi (2010), durante este período de festa popular, as leis sociais normais são mais ou menos suspensas, incluindo a atividade agrícola, de forma a corresponder ao grande momento da festa comunitária. Nesse período o líder comunitário fica mais próximo da população sob a sua jurisdição e são organizadas campanhas de apanha de makanyi (plural de $a k a n y i$ - fruto de $n$ 'kanyi - árvore) para a preparação da bebida na casa do líder local. As famílias

\footnotetext{
${ }^{5}$ Todos os dados desta secção (descrição do ritual de ukanhy) foram estraídos da minha monografia de licenciatura: COSSA, Dulcídio M. A. O Ritual de Ukanhy: uma tradição na modernidade. 2013. 70 f. Monografia (Licenciatura em Sociologia) - Faculdade de Letras e Ciências Sociais, Universidade Eduardo Mondlane, Maputo, 2013.

${ }^{6}$ Nome em xichangana, língua local, que significa época da bebida de canhú.

${ }^{7}$ Nome em língua local (xichangana).

${ }^{8}$ Nome atribuído ao canhoeiro em língua local (xichangana).
} 
que não participam nas atividades preparatórias têm a obrigação social de trazer alguma quantidade de bebida no dia marcado para o ritual de ukanyi (VALOI, 2010).

Pode-se entender que essa celebração movimenta quase toda uma estrutura de vida social, dinamizando e refazendo ados indivíduos, portanto, envolve as dimensões sociocultural, política e econômica, mostrando que não só dinamiza a rotina das pessoas, mas também a dos lugares onde o ritual acontece, transformando-os continuamente.

O ritual de ukanyi começa por uma etapa, uma espécie de ritual denominado kuhawula mindzheko ${ }^{9}$, que segundo os entrevistados, é o momento em que se anuncia a abertura oficial da época de ukanyi e a partir deste ato fica liberado o seu consumo, o que significa ser expressamente proibido a sua ingestão antes de realizado o ritual sob o risco de ser penalizada a pessoa que eventualmente transgredir esta regra.

Kuhawula mindzheko é o período em que se anuncia aos ancestrais a chegada da época de ukanyi e que se roga aos mesmos para o sucesso desta. Não se pode beber ukanyi sem antes se comunicá-los (COSSA, 2013). Estas proibições levam a pensar num conjunto de normas que condicionam a realização do ritual e orientam a conduta dos indivíduos e consequentemente nos remetem a questões jurídicas, ou seja, ao que chamaríamos de direito intercultural, aqui relacionado ao conjunto de normas tradicionalmente instituídas ou institucionalizadas que regem um grupo ou grupos de indivíduos.

Cumprido o kuhawula mindzheko e posteriormente liberado o consumo de ukanyi vem a outra etapa: a grande festa ou o auge do ritual de ukanyi, denominado xikuwha. Essa é a festa tradicional popular de ukanyi (a maior e a mais valorizada), a qual simboliza o encontro entre os membros de uma comunidade ou de várias comunidades. Portanto, é a celebração em que os sujeitos confraternizam, convivem e interagem uns com os outros celebrando a época de ukanyi (COSSA, 2013).

Entretanto, não é simplesmente uma reunião entre as pessoas, mas um encontro destas com os ancestrais por via de alguns atos rituais, como o kuphahla ${ }^{10}$, tida com uma prática presente em todos os rituais de ukanyi e em todas as etapas do ciclo da época de ukanyi. Mais do

\footnotetext{
${ }^{9}$ Nome atribuído a este ritual em língua local (xichangana).

${ }^{10}$ Nome em língua local (xi changana) atribuído ao ritual de invocação dos ancestrais.
} 
que para invocar os antepassados existe também a crença comum de que kuphahla é o meio através do qual estes bebem e desfrutam do ukanyi e mantêm-se presentes no ritual. Portanto, estas crenças são comportamentos de senso comum que segundo Garfinkel (1967) são os constituintes necessários de todo o comportamento socialmente organizado. E, é assim que os sujeitos veem, descrevem e propõem em conjunto uma definição da situação social do ritual (COSSA, 2013).

Após o xikuwha, realiza-se um último ato: kuhayeka mindzheko ${ }^{11}$, esta é a etapa na qual se anuncia o fim da época de ukanyi e em que se presta agradecimento aos ancestrais pelo sucesso da época ou faz-se a exposição dos dissabores ocorridos, pedindo para que não se repitam em situações vindouras.

Importa também afirmar que o ritual de ukanyi é geralmente dirigido pelo líder local, que é o superior hierárquico e representante da comunidade, sendo este o primeiro a beber ukanyi, e que a cerimônia é dirigida em língua local xiChangana para o caso de Macuane e xiRhonga em Marracuene, por sinal estas são as línguas mais fluentes durante o ritual, uma vez que constituem os idiomas nativos destes contextos sociais. Através da etnometodologia de Garfinkel (1967) isso equivale à indicialidade, segundo a qual, a vida social se constitui através da linguagem da vida de todos os dias, tendo em vista que as expressões indiciais, neste caso de xiChangana e xiRhonga, tiram o seu sentido do próprio contexto social. Ademais, falar xiChangana e/ou xiRhonga implica domínio da linguagem institucional comum, que é um elemento fundamental para que os indivíduos se sintam ou sejam considerados membros da comunidade, pois a noção de membro não se refere a pertença social, mas ao domínio da linguagem natural, atendendo e considerando o contexto social (COSSA, 2013). Assim, o ritual de ukanyi é também um momento de valorização, revitalização e afirmação da língua tradicional ao mesmo tempo que vai sendo intercalada com o português.

Para a consecução do ritual de ukanyi as comunidades organizam-se da seguinte forma: por um lado as mulheres encarregam-se de recolher makanyi ${ }^{12}$ e juntá-lo num único lugar. No período da maturação de makanyi elas voltam a encontrar-se para a preparação de ukanyi,

\footnotetext{
${ }^{11}$ Nome atribuído a este ritual em língua local (xi changana).

${ }^{12}$ Nome em língua local (xi changana) atribuído aos frutos do n’kanhy (canhoeiro).
} 
contudo, há aquelas que por motivos diversos optam em prepará-lo individualmente e depois transportá-lo para o local do ritual. É também tarefa delas confeccionar os alimentos a serem consumidos na cerimônia, e como geralmente a época de ukanyi coincide com a época de colheita, são comuns os pratos tradicionais podendo até haver sacrifício de animais. Enquanto isso, por outro lado, os homens se responsabilizam por sacrificar tais animais.

A etapa da preparação do ritual de ukanyi é, no entanto, um dos momentos em que homens e mulheres através das conversas compartilham seus conhecimentos, suas vivências e as experiências do seu dia-a-dia, e mais ainda, é um período no qual homens e mulheres encontramse mais próximos uns dos outros, unidos pela mesma causa.

Desde o início ou desde a etapa da preparação do ritual de ukanyi, tanto as mulheres quanto os homens vão criando e estabelecendo uma rede de relações presentes nas interações sociais que lhes são sujeitos pela divisão social do trabalho, como diria Durkheim (2000). É interagindo uns com os outros e dando origem a um entrelaçamento forte de relações sociais que se garante o sucesso do ritual de ukanyi bem como da época em geral e ao fazer isso, parafraseando Garfinkel (1967), vão criando uma ordem negociada, temporária, frágil que deve ser permanentemente reconstruída. Portanto, essa etapa permite que haja uma interação por via de canções e de conversas que vão sendo tecidas em torno do cotidiano fazendo com que seja um momento de manutenção das relações sociais por excelência (COSSA, 2013; 2017).

No local do ritual, homens sentam-se de um lado e as mulheres de outro. Ukanyi é colocado em potes de barro denominados khuwane ${ }^{13}$ e ao lado dos potes vão os alguidares de barro chamados lihisu $^{14}$, onde são conservadas as cabaças $n d z e k o^{15}$ usadas para servir e beber ukanyi. No final do ritual os alguidares são usados para conservar o hongwe ${ }^{16}$, o qual contitui a bebida que fica no fundo do pote. Acredita-se que o alto teor afrodisíaco de ukanyi está mais concentrado no hongwe, já que tem o poder de fortalecer a potência sexual, daí que, reza a

\footnotetext{
${ }^{13}$ Nome em língua local (xichangana) atribuído ao pote usado para conservar ukanyi. Não é de uso exclusivo para a conservação de ukanyi, pois pode ser usado também para conservar água.

${ }^{14}$ Nome em língua local (xichangana) atribuído ao alguidar que conserva ndzheko e hongwe.

${ }^{15}$ Nome em língua local (xichangana) atribuído as cabaças usadas para beber ukanyi.

${ }^{16}$ Nome em língua local (xichangana) atribuído à parte mais densa de ukanyi onde existe a maior concentração do teor afrodisíaco desta bebida tradicional.
} 
tradição que o hongwe só deve ser consumido por indivíduos que tenham parceiros, sobretudo homens, na tentativa de evitar situações de adultério ou traição.

Para manter o ritual de ukanyi mais animado, o mesmo é sistematicamente acompanhado de canções folclóricas, embaladas ao ritmo de palmas, que retratam o cotidiano dos indivíduos. Os cânticos são simultaneamente acompanhados de danças tradicionais, entretanto, tanto estas como aqueles, mais do que animar, são mecanismos legitimadores das interações sociais estabelecidas, uma vez que pressupõem uma relação entre quem as canta e dança e quem as acompanham.

É extremamente fundamental descrever o ritual de ukanyi desde a etapa de preparação até o seu culminar, porque compõem a matéria por meio da qual podemos enxergar as várias transformações dos espaços do ritual através das interações que ali se estabelecem, a forma como os indivíduos se relacionam, as canções, a dança, a ordenação dos objetos no espaço e o modo como esses objetos são significados. Em suma, a descrição do ritual de ukanyi permite-nos compreender como os lugares se transformam em espaços de ritual e como a vida social desses espaços se modifica parcialmente com o ritual de ukanyi.

\section{Das perspectivas ao debate: o ritual de ukanyi, espaços e lugares, lugares de memória e morfologia social}

Aqui me interessa propor de forma breve as perspectivas com as quais tecerei a discussão, respectivamente, as de Michel de Certeau, em que recuperarei as noções de espaços e lugares, de François Hartog com os lugares de memória e Marcel Maus com a idéia de morfologia social e consequentemente a discussão propriamente dita entre estas noções e os dados presentes no artigo.

Segundo Certeau (2011) em sua obra Relatos de espaço na invenção do cotidiano, um lugar é a ordem, seja qual for, segundo a qual se distribuem elementos nas relações de coexistência. Aí se acha excluída a possibilidade de duas coisas ocuparem o mesmo ambiente. Dessa forma, impera a lei do próprio, isto é, os elementos considerados se acham uns ao lado dos outros, cada um situado num lugar próprio e distinto que o define. Há, portanto, uma configuração instantânea de posições que implica uma indicação de estabilidade. 
Existe espaço sempre que se tomam em conta vetores de direção, quantidades de velocidade e a variável tempo. O espaço é um cruzamento de móveis, é de certo modo animado pelo conjunto dos movimentos que aí se desdobram, é o efeito produzido pelas operações que o orientam, o circunstanciam, o temporalizam e o levam a funcionar em unidade polivalente de programas conflitanes ou de proximidades contratuais (CERTEAU, 2011).

Diversamente do lugar, o espaço não tem nem a univocidade nem a estabilidade de um próprio, de modo a remeter à instabilidade. Contudo, lugar e espaço não são categorias antagônicas, mas níveis diversificados que se interdependem. O primeiro transforma-se dialeticamente com a dinâmica social adquirindo aspecto do segundo, sendo este um lugar praticado. Assim, a rua geometricamente definida por um urbanismo é transformada em espaço pelos pedestres (CERTEAU, 2011) e dizer que a rua é transformada pelos pedestres implica afirmar que estes a transformam pelo fato de estarem interagindo uns com os outros, ou seja, as relações sociais estabelecidas pelos indivíduos constroem e reconstroem o espaço, assim como o desconstroem criando novos espaços. Os espaços rural e urbano também assim se constituem.

Deste modo, pela interação dos diversos atores sociais (participantes/espectadores) o lugar onde decorre o ritual torna-se um lugar praticado, transformando-se assim em espaço de ritual de ukanyi. Esta visão leva a pensar que o espaço rural (Macuane) e o urbano (Marracuene) na época de ukanyi transformam-se também em espaços de ritual de ukanyi.

Assim, assumindo a perspectiva de lugares e espaços de Certeau (2006) podemos constatar que, durante o ano, fora da época de ukanyi, Marracuene e Macuane são lugares em que a rotina cotidiana dos indivíduos decorre normal e tranquilamente e as relações sociais são de fraca intensidade ensejando lugares estáveis.

Todavia, entre os meses de janeiro, fevereiro e março, período em que decorre o ritual de ukanyi, estes lugares se transformam quase que radicalmente, reconfigurando-se em ambientes instáveis, ou seja, em espaços praticados que se destacam pela ênfase na instabilidade social. É durante essa época que se verifica uma grande movimentação de pessoas nas áreas rural e urbana, entre Macuane e Marracuene.

Os indivíduos procuram se reunir para celebrar o ritual de ukanyi e a urgência em participar é mais forte. Tal como descrito acima, desde a fase de preparação do ritual, é 
organizado todo um aparato de elementos que mobilizam os sujeitos a se empenharem para o seu sucesso, de maneira que os indivíduos não só se mobilizam como também cresce a interação entre eles, tornando as relações sociais mais intensificadas e aumentando a tensão e a dinâmica daqueles espaços.

Portanto, estes fatos fazem com que Macuane e Marracuene transformem-se em lugares e/ou espaços caracterizados pelo seu alto nível de instabilidade, onde a estrutura social se modifica quase que completamente, dando vazão a novas formas de relações entre os indivíduos. Tais formas podem ser instantâneas, momentâneas ou duradouras.

Assim, não obstante Certeau (2006) pontue que todos os espaços são praticados, o que há de notável no ritual de ukanyi é a mudança que se verifica durante a época ritualística, na qual a estabilidade é substituída pela instabilidade social. Esta relação fica mais evidente na análise que faço a seguir, usando Marcel Mauss.

Mas como estes espaços praticados podem ser analisados através de uma perspectiva "maussiana"?

No seu Ensaio sobre as variações sazonais das sociedades esquimós, Mauss (1906) propõe-se estudar a morfologia social das sociedades esquimós ${ }^{17}$. Entende-se morfologia social, tal como o autor aponta, como a ciência que estuda para descrever e explicar o substrato material das sociedades, isto é, a forma que elas ostentam ao se estabelecerem no solo, o volume e a densidade da população, a maneira como ela se distribui, bem como o conjunto das coisas que servem de base para a vida coletiva.

Tal como no contexto esquimó, a morfologia social de Macuane e Marracuene varia num dado período do ano. A partir desse ponto, como mencionado outrora, fora da época de ukanyi, de abril até novembro, período predominantemente caracterizado pelo inverno, a vida nessas regiões é praticamente calma, quase que estável. Contudo, durante os meses de dezembro, janeiro, fevereiro e março, período dos rituais de $u k a n y i$, predominantemente caracterizado pelo

${ }^{17} \mathrm{O}$ que faz dos esquimós um campo de estudo privilegiado é o fato de sua morfologia não ser a mesma nos diferentes momentos do ano. Conforme as estações, a maneira como os homens se agrupam, a extensão, a forma de suas casas, a natureza de suas instituições muda completamente. Os esquimós se distribuem de formas desiguais no verão e no inverno. No verão tem uma determinada característica e no inverno outra. Portanto, estas variações permitem estudar a maneira pela qual a forma material dos agrupamentos humanos, isto é, a natureza e a composição de seu substrato, afeta os diferentes modos da atividade coletiva (MAUSS, 1906). 
verão, a vida modifica-se, os encontros entre as comunidades aumentam, os indivíduos tornam-se mais próximos uns dos outros para interações cada vez mais interpessoais contrariando a impessoalidade do período fora desta época. Homens e mulheres, líderes políticos, todos empenhados em garantir o sucesso da época juntam as forças e organizam as festas rituais e nesse âmbito as práticas tornam-se mais frequentes na vida dos indivíduos.

Nesta época de ukanyi, ao mesmo tempo em que algumas normas sociais são interrompidas em prol da realização da cerimônia, outras são ativadas. Tal como refere Valoi (2010), por exemplo, durante este período de festa popular as leis sociais comuns são mais ou menos suspensas, incluindo a atividade agrícola, em contrapartida, outras são iniciadas. Deste modo, o direito intercultural, aquele ligado às normas tradicionais se reestrutura para se adaptar à época de ukanyi.

A época do ritual de ukanyi (verão) é também caracterizada como momento de encontro e exaltação dos antepassados e de transmissão dos valores culturais de geração para geração. Representa um momento coletivo em que se reafirma o sentimento de grupo e até de pertença à comunidade. Assim, as diferenças religiosas são quase que esquecidas para dar lugar ao espírito de partilha de valores e crenças culturais (tradicionais e modernas). Contudo, essa divisão não implica necessariamente a aceitação desses valores por parte dos indivíduos, mas o respeito e reconhecimento pela diferença, não obstante, fora da época de ukanyi (inverno) seja bem notável a heterogeneidade religiosa.

Não só na época da festa de ukanyi, mas também fora dela, intensificam-se as relações entre o espaço rural (Macuane) e urbano (Marracuene), na medida em que as pessoas vão se deslocando de um espaço para o outro com a finalidade de participar do ritual. Tem-se que a morfologia social transforma-se e reconfigura-se com os rituais e os espaços rural e urbano se tornam instáveis, como diria Certeau (2006).

Durante o período de malanga (verão), que é a época de ukanyi, os macuaneses e marracueneses vivem num estado de exaltação religiosa-tradicional contínua. É o momento em que todos os mitos e os contos transmitem-se de uma geração a outra. Essa vida religiosa de exaltação, de cultos aos antepassados, além de intensa, apresenta um caráter muito particular, tendo em vista ser eminentemente coletiva, o que contrasta com a vida de vuxika (inverno - 
época pós-ukanyi). Com isso, não se pretende dizer simplesmente que as festas de ukanyi são celebradas em comum, mas que nelas transpira de todas as maneiras o sentimento que a comunidade tem de si mesma, de sua unidade. Portanto, não são coletivas apenas no sentido de que uma pluralidade de indivíduos reunidos delas participa, mas que são assunto do grupo. Essa posição da vida de malanga (verão) e de vuxika (inverno) não se traduz apenas nos ritos, nas festas, nas cerimônias religiosas, mas também afeta profundamente as ideias, as representações coletivas, em suma, toda a mentalidade do grupo (Mauss, 1906).

A época de ukanyi (malanga - verão) é o período em que a sociedade, fortemente concentrada, encontra-se num estado crônico de efervescência e superatividade. Como os indivíduos estão mais intimamente próximos uns dos outros, as ações e reações sociais são mais numerosas, mais frequentes, mais contínuas, trocam-se idéias, sentimentos se intensificam e se reforçam mutuamente. O grupo, sempre em ação, sempre presente aos olhos de todos, tem mais o sentimento de si mesmo e assim ocupa um lugar maior na consciência dos indivíduos. Já na época pós-ukanyi (vuxika - inverno), os laços sociais se afrouxam e as relações intensas fazem- se mais raras.

Pode-se afirmar que, enquanto o tempo cotidiano, época pré e pós-ukanyi é marcado pela horizontalidade e pela relativa dispersão entre os indivíduos, o tempo do ritual festivo, época de ukanyi, desloca-se como diriam Gonçalves e Contins (2009) progressivamente para a verticalidade, uma vez que a ênfase está na concentração entre os irmãos e nas relações de troca entre os seres humanos e os antepassados, entre o mundano e o supramundano.

Portanto, podemos afirmar tal como Mauss (1906) que a vida social em Macuane e Marracuene apresenta-se sob duas formas oponíveis e paralelas em sua ampla morfologia. Assim, os indivíduos têm duas formas de se agrupar, de se comportar e a essas duas maneiras de agrupamento correspondem dois sistemas jurídicos, duas morais e duas espécies de vida religiosa (ritualística), o que em Certeau (2006) implicaria afirmar que tais formas nos remetem a dois espaços distintos em épocas diferentes, um estável (época pós-ukanyi) e outro, instável (época de ukanyi). Contudo, não diria que essas duas formas de vida social seriam necessariamente oponíveis como Marcel Mauss sugere, mas que se interpenetram e complementam-se mutuamente, e mais ainda, essa tendência de tensão seria a condição necessária para galvanizar a 
dinâmica daqueles espaços sociais, tornando-os lugares praticados, espaços antropológicos dialeticamente construídos e/ou constituídos.

Ora, seriam então, esses espaços praticados e antropológicos, lugares de memória?

Hartog (2006) em seu artigo Tempo e Patrimônio procura fazer uma análise histórica do tempo, tendo em conta o passado, presente e futuro. Mas, sobretudo, sua análise está centrada no presente, o que o autor chama de presentismo.

Assim, para conduzir sua pesquisa recupera a noção de regime de historicidade, que de forma restrita é como uma sociedade trata seu passado. De maneira mais ampla, designa a modalidade de consciência de si de uma comunidade humana. Assim, o ritual de ukanyi é em simultâneo uma forma de revitalização do passado para reavivar sobretudo os valores dos indivíduos no presente e por via dessa revitalização é também uma forma de garantir a continuidade dessa prática ritual e consequentemente um meio de afirmação de identidade que por meio dele procura fazer um apelo de consciência de si, neste caso dos grupos sociais de Macuane e Marracuene.

Mais do que isso, regime de historicidade deveria, segundo Hartog (2006), servir para iluminar maneiras de ser no tempo, ou seja, iluminar as formas de experiência do tempo, aqui e lá, hoje e ontem. Tendo em vista essa concepção, o ritual de ukanyi hoje conserva valores tradicionais e simbolismos que são o espelho de como ele decorria no passado e de como se entrelaçavam as relações sociais entre os indivíduos tanto em Macuane e em Marracuene ao mesmo tempo que o ritual reconfigurado com novas formas, novos valores, novos simbolismos e até significados representa as dinâmicas, habitus e os modos de vida do tempo presente com influências da modernidade, dos habitus do espaço urbano.

Assim, ao se centrar no presentismo, François Hartog (2006) recupera as noções de memória e patrimônio. Segundo o autor, este se impôs como a categoria dominante, englobante, evidente da vida cultural e das políticas públicas, remetendo aos lugares de memória, tal como se pode constatar na definição dada na lei de 1993 sobre o patrimônio monumental: "nosso patrimônio é a memória de nossa história e símbolo de nossa identidade nacional” (HARTOG, 2006, p. 266). 
Passando para o lado da memória, o patrimônio se torna memória da história e como tal símbolo de identidade. Memória, patrimônio, história, identidade, nação, encontram-se reunidos. Nesta nova configuração, o patrimônio se encontra ligado ao território e à memória, que operam um e outro como vetores da identidade (HARTOG, 2006).

Portanto, Hartog (2006) permite compreender os espaços de ocorrência do ritual de ukanyi como lugares de memória, pois ao celebrá-lo, comemora-se e compartilha-se um conjunto de valores e crenças, faz-se um apelo à pertença social e assim partilha-se um conjunto de memórias coletivas que perfazem a história comum, afirmando-se a identidade sociocultural.

\section{Considerações finais}

Assumindo a perspectiva de lugares e espaços de Certeau (2006) pode-se constatar que fora da época de ukanyi, Maputo e Macuane são lugares em que a rotina dos indivíduos decorre normalmente e as relações sociais são de fraca intensidade, remetendo a lugares estáveis. Contudo, entre os meses de janeiro, fevereiro e março período em que decorre o ritual de $u k a n y i$, estes lugares se transformam quase que radicalmente, reconfigurando-se em regiões instáveis, momento em que os indivíduos procuram se reunir e celebrar o ritual de ukanyi aumentando a interação entre eles, tornando as relações sociais mais intensas e aumentando a tensão e a dinâmica daqueles espaços.

Estes fatos fazem com que Macuane e Marracuene durante o ritual se tornem lugares e/ou espaços praticados, instáveis, onde a estrutura social se modifica quase que completamente, dando lugar a novas formas de relações entre os indivíduos, instantâneas, momentâneas ou duradouras. Assim sendo, pode-se afirmar que a morfologia social dessas regiões varia de acordo com o período, com as estações do ano, nas quais, numa temos um ambiente de estabilidade e noutra, instabilidade.

Por fim, elas podem ser compreendidas como lugares de memória, pois ao se celebrar o ukanyi, comemora-se e compartilha-se um conjunto de valores e crenças que resultam num sentimento de pertença social que acabam assumindo uma noção de identidade sociocultural, paralelamente, é possível afirmar que a revitalização do ritual de ukanyi, a sua contínua reconfiguração, o interesse em se realizá-lo cada vez mais, a preocupação em afirmar os valores, 
as crenças, enfim, a identidade, rementem à preocupação dos grupos sociais em preservá-lo o que por sua vez leva a pensar na preocupação dos indivíduos em relação ao presente, fazendo referência ao presentismo mencionado por Hartog (2006).

\section{Referências bibliográficas}

CERTEAU, Michel de. "Relatos de espaço". In: A invenção do cotidiano. Artes de fazer 1. Petrópolis: Editora Vozes, 2011, p. 182-200.

COSSA, Dulcídio M. A. O Ritual de Ukanhy: uma tradição na modernidade. 2013. Monografia (Licenciatura em Sociologia) - Faculdade de Letras e Ciências Sociais, Universidade Eduardo Mondlane, Maputo.

Mhamba ya ukanyi (O ritual de ukanyi): uma tradição na modernidade entrelaçamentos do rural e urbano. 2017. Dissertação (Mestrado em Ciências Sociais) - Instituto de Ciências Sociais, Universidade do Estado do Rio de Janeiro, Rio de Janeiro.

GARFINKEL, Harold. Estudos da etnometodologia. Cambridge: Polity presse, 1967.

GONÇALVES, José R. S.; CONTINS, Marcia. “A escassez e a fartura: categorias cosmológicas e subjetividade nas festas do Divino Espírito Santo entre os açorianos imigrantes no Rio de Janeiro". In: CAVALCANTI, Maria L. V. C; GONÇALVES, José R. S. (Orgs). As festas e os dias: ritos e sociabilidades festivas. Rio de Janeiro: Contra Capa Livraria Ltda, 2009.

HARTOG, François. Tempo e patrimônio. Varia Historia, Belo Horizonte, v.22, n36, jul/dez. 2006, p. 261-273.

MAUSS, Marcel. "Ensaio sobre as variações sazonais das sociedades esquimós”. In: Sociologia e antropologia. São Paulo: Ed. Cosac e Naify. 2003, p. 423-505.

VALOI, Alberto. Ukanhy Festival: N'kuvu wa wukanhy. 2010. Disponível em $<<$ http://www.dekhanaproducoes.com/news/ucanhy\%20festival\%20-

\%20n\%C2\%B4kuvu\%20wa\%20wukanhy/>> Acessado em: 2 Mar. 2012.

Recebido em: Julho de 2017

Aprovado em: Dezembro de 2017

INTRATEXTOS, Rio de Janeiro, vol. 8, n.1, 2017, p. 247-261. ISSN 2176-6789. 